\title{
Response of an ocean general circulation model to wind and thermodynamic forcings
}

\author{
A Chakraborty*, H C Upadhyaya and O P Sharma \\ Centre for Atmospheric Sciences, Indian Institute of Technology, New Delhi 110016, India \\ *Present address: Mody College of Engineering and Technology, Lakshmangarh 332 311, \\ Sikar (Rajasthan), India.
}

\begin{abstract}
The stretched-coordinate ocean general circulation model has been designed to study the observed variability due to wind and thermodynamic forcings. The model domain extends from $60^{\circ} \mathrm{N}$ to $60^{\circ} \mathrm{S}$ and cyclically continuous in the longitudinal direction. The horizontal resolution is $5^{\circ} \times 5^{\circ}$ and 9 discrete vertical levels. First a spin-up experiment has been done with ECMWF-AMIP 1979 January mean fields. The wind stress, ambient atmospheric temperature, evaporation and precipitation have been used in order to derive mechanical and thermodynamical surface forcings. Next, the experiment has been extended for another 30 years (3 cycles each of 10 year period) with varying surface boundary conditions (from January 1979 to December 1988 of ECMWF-AMIP monthly fields for each cycle) along with 120 years extended spin-up control run's results as initial conditions. The results presented here are for the last 10 years simulations. The preliminary results of this experiment show that the model is capable of simulating some of the general features and the pattern of interannual variability of the ocean.
\end{abstract}

\section{Introduction}

The world ocean is one of the important components of the climate system. On timescales from weeks to millennia, the dynamics of climate is strongly controlled by the behavior of the oceans since the ocean circulation distributes large amounts of heat around the planet. Recent modelling studies and observations suggest that variations in the ocean circulation are responsible for natural climate fluctuations in the past (Broecker 1991; Weaver and Hughes 1992). The equatorial Pacific Ocean also exhibits the most prominent interannual signal of climate variability known as ElNiño. During such events, warm surface waters appear for several months over almost the entire equatorial zone. A number of model studies have been carried out by many researchers (Philander and Pacanowski 1980, 1981; Philander 1981; Latif et al 1987) which include the thermodynamic processes (the necessary ingredients) to predict the sea surface temperature (SST). These studies have clearly demonstrated the ability of OGCMs to reproduce the observed variations in the thermal and velocity structure of the equatorial ocean in response to the imposed wind forcing. Although these OGCMs have been used to study different physical phenomena in the ocean (such as turbulent eddies in the mid-latitudes, the thermohaline circulation, meridional heat fluxes, the general circulation of the Pacific, Atlantic and Indian Ocean etc.), but the different ocean models have several common deficiencies in reproducing the observed annual average state and seasonal cycle of SST (Stockdale et al 1993; Mechoso et al 1995). On examining the results of 11 coupled oceanatmosphere models, Mechoso et al (1995) have pointed out the following three main problematic areas:

- the structure of SST along the equator involving the equatorial Pacific cold tongue: most of the model simulated SST values are $1^{\circ}-3^{\circ} \mathrm{C}$ colder than observed in the central Pacific and complex structure near the coasts in contrast to the simplicity of the observed structure.

- the north-south structure of SST in the eastern Pacific: the warmer SSTs over a broad region in the

Keywords. ECMWF; AMIP; WOCE; stretched-coordinate; interannual variability. 
eastern Pacific south of the equator along with a large eastward extension of the lobe of the western Pacific warm pool produces double ITCZ and this is unrealistic.

- the meridional extent of the warm pool: few models reproduce the region of SSTs warmer than $29^{\circ} \mathrm{C}$ covering the western Pacific warm pool but other models produce the narrow warm pool which is too cool.

They explained that the narrowness of the cold tongue strongly implicates dynamics specific to the equatorial upwelling zone and the unrealistic structure of cold tongue, double ITCZ as well as narrow warm pool in the western Pacific causes climatic drift in case of coupled modelling. Another problem arises from the usage of different numerical techniques for atmospheric and ocean circulation components in a coupled model. The atmospheric dynamics is generally treated by spectral/gridpoint method whereas the ocean dynamics is treated by the grid point method only. Even the gridpoint methods for the ocean and atmosphere may differ. So there is a likelihood that numerical errors of atmospheric circulation are transferred to ocean simulations and vice-versa (Battisti and Hirst 1989). In order to resolve this problem, an $a$ priori consistent representation (discrete) of mathematical operators appearing in the governing equations of both oceanic and atmospheric circulation is required. Therefore, in view of the latter problem, an $a b$ initio development of a three dimensional OGCM in stretched coordinates with zoom capability over an area of interest has been accomplished here and referred to in the text as the Indian Institute of Technology Delhi Ocean General Circulation Model (IITDOGCM). This model will be eventually coupled to a stretched coordinate AGCM to study the dynamics of climate and its variations, intraseasonal and interannual variability of monsoon and for El-Niño/Southern Oscillation (ENSO) predictions. Moreover, the World Ocean Circulation Experiment (WOCE) programme emphasized advancing the development of ocean models, including refinements of physical parameterizations and improving the numerical schemes. The WOCE Scientific Steering Group agreed that many model innovations are conceived by small research teams located in universities or oceanographic institutions and emphasized that "the model development can be distributed among individuals and group" for advancing the research in this field (WCRP, WMO/TD-No. 855, October 1997). The development of this model is much in line with this philosophy.

And due to all these reasons, the OGCM codes are not downloaded inspite of its availability in the internet and Chakraborty et al 1998 has been used for this study which is different from other models both in the formulation and resolution. Model resolution plays an important role in accurately simulating the fine features of ocean circulation. However, finer resolution puts excessive burden on computers with their efficiency restricted to technology which, in turn, has a physical limit. Nevertheless, finer resolution can be achieved with the help of coordinate-stretching (Sharma et al 1987) without increasing the burden on a machine which is being used for model execution. Better resolution models are required to resolve the steep gradients which may develop, in some oceanic regions, as the dynamics evolves. In a global model this can be easily done by introducing stretching functions for respective coordinates. The coordinatestretching offers the advantage of achieving enhanced resolution in an area of interest while resolution remaining coarser over the rest of the globe. It is thus possible to increase the efficiency of models, mathematically, via coordinate-stretching. Once the parameters in a stretching function is fixed, it gives a particular resolution which is finer where stretching is maximum and coarser wherever it is minimum. The resolution can only be changed by altering the values of the parameters in a stretching function. In this sense, the approach may suffer from some degree of rigidity and may appear to be less flexible than the nested-grid approach. Despite this limitation, it has the advantage that both the barotropic and baroclinic components of the flow are resolved and interact in a natural way as they evolve during the course of model execution. Some of these advantages make this approach preferable over other approaches.

The wind field used for these simulation experiments are derived from ECMWF AMIP archives. The experiment was performed by spinning up the model from a state of rest with prescribed thermodynamic fields and mean winds, and subsequently forcing the model with varying mean monthly fields for 30 years (3 cycles) with the 10 years AMIP cycle data. In this paper, we present a preliminary analysis of the last 10 years simulation of the interannual variability of the model.

The paper is arranged as follows. The model is introduced in section 2. The initial and boundary conditions are discussed in section 3 . In section 4 , we discuss the design of experiments. Section 5 reports the results of spin-up and simulation experiments. Conclusions are given in section 6 .

\section{Mathematical formulation of IITD-OGCM}

The stretched-coordinate IITD-OGCM used in this study is a finite difference treatment of the primitive equations of motion using the Boussinesq and hydrostatic approximations in spherical coordinates with nine $(10,30,75,250,500,1000,1500,2000$ and $3000 \mathrm{~m})$ discrete vertical levels having flat bottom topography. The system of equations is discretized on a Arakawa 
C-type staggered grid. The coordinate stretching is handled easily by formulating the equations, as those utilized for the OPA model by Delecluse et al (1993), in terms of covariant or contravariant vector components (Sadourny 1975). The model equations are:

dynamical equations:

$$
\begin{aligned}
\frac{\partial u}{\partial t} & =m_{u}-M_{u}-\frac{1}{H} \frac{\partial}{\partial y}\left(\frac{\partial \Psi}{\partial t}\right), \\
\frac{\partial v}{\partial t} & =m_{v}-M_{v}+\frac{1}{H} \frac{\partial}{\partial x}\left(\frac{\partial \Psi}{\partial t}\right), \\
\frac{\partial}{\partial x} & {\left[\frac{1}{H} \frac{\partial}{\partial x}\left(\frac{\partial \Psi}{\partial t}\right)\right]+\frac{\partial}{\partial y}\left[\frac{1}{H} \frac{\partial}{\partial y}\left(\frac{\partial \Psi}{\partial t}\right)\right] } \\
= & \frac{\partial}{\partial x}\left(M_{v}\right)-\frac{\partial}{\partial y}\left(M_{u}\right)
\end{aligned}
$$

with:

$$
\begin{aligned}
m_{u}= & +Z v-\frac{\partial B}{\partial x}-w \frac{\partial u}{\partial z}+A_{m}\left[\frac{\partial^{2} u}{\partial x^{2}}+\frac{\partial^{2} u}{\partial y^{2}}\right] \\
& +\frac{\partial}{\partial z}\left(k_{m} \frac{\partial u}{\partial z}\right) \\
m_{v}= & -Z u-\frac{\partial B}{\partial y}-w \frac{\partial v}{\partial z}+A_{m}\left[\frac{\partial^{2} v}{\partial x^{2}}+\frac{\partial^{2} v}{\partial y^{2}}\right] \\
+ & \frac{\partial}{\partial z}\left(k_{m} \frac{\partial v}{\partial z}\right)
\end{aligned}
$$

where,

$$
\begin{aligned}
M_{u} & =\frac{1}{H} \int_{-H}^{0} m_{u} \mathrm{~d} z, \quad M_{v}=\frac{1}{H} \int_{-H}^{0} m_{v} \mathrm{~d} z \\
Z & =\left[f A+\frac{\partial v}{\partial x}-\frac{\partial u}{\partial y}\right], \quad B=\frac{p}{\rho_{0}}+\frac{1}{2}\left[u^{2}+v^{2}\right],
\end{aligned}
$$

$f=2 \Omega \sin \phi=$ coriolis parameter and area $(A)=$ $\zeta \eta=a^{2} x^{\prime} y^{\prime} \cos \phi$.

tracer equations:

$$
\begin{aligned}
\frac{\partial T}{\partial t}= & -\frac{\partial(u T)}{\partial x}-\frac{\partial(v T)}{\partial y}-\frac{\partial(w T)}{\partial z}+A_{h}\left[\frac{\partial^{2} T}{\partial x^{2}}+\frac{\partial^{2} T}{\partial y^{2}}\right] \\
& +\frac{\partial}{\partial z}\left(k_{h} \frac{\partial T}{\partial z}\right), \\
\frac{\partial S}{\partial t}= & -\frac{\partial(u S)}{\partial x}-\frac{\partial(v S)}{\partial y}-\frac{\partial(w S)}{\partial z}+A_{h}\left[\frac{\partial^{2} S}{\partial x^{2}}+\frac{\partial^{2} S}{\partial y^{2}}\right] \\
& +\frac{\partial}{\partial z}\left(k_{h} \frac{\partial S}{\partial z}\right),
\end{aligned}
$$

hydrostatic equation:

$$
\frac{\partial P}{\partial z}=-\rho g,
$$

continuity equation:

$$
\frac{\partial u}{\partial x}+\frac{\partial v}{\partial y}+\frac{\partial w}{\partial z}=0
$$

equation of state:

$$
\rho=\rho_{0}\left[1-\alpha\left(T-T_{0}\right)+\beta\left(S-S_{0}\right)\right]
$$

where $T_{0}$ and $S_{0}$ are climatological temperature and salinity respectively.

\subsection{Boundary conditions}

The initial state of the ocean was taken as rest in which the upper boundary conditions were prescribed from mean January 1979 of AMIP archives. The initial state for salinity and temperature was taken from Levitus annual mean climatology. The boundary conditions are the no-slip condition at the bottom and the free slip condition at the boundaries. The model is forced at the surface by wind stress, heat and salinity fluxes:

$$
\begin{aligned}
& \left(w, k_{m} \frac{\partial u}{\partial z}, k_{m} \frac{\partial v}{\partial z}, k_{h} \frac{\partial T}{\partial z}, k_{h} \frac{\partial S}{\partial z}\right) \\
& =\left(0, \frac{\tau_{x}}{\rho_{0}}, \frac{\tau_{y}}{\rho_{0}}, \frac{Q_{T}}{\rho_{0} C_{p}}, \frac{Q_{S}}{\rho_{0}}\right) \text { at } z=0 .
\end{aligned}
$$

The vertical velocity and fluxes of heat and salinity vanish at the bottom of the ocean:

$$
\begin{gathered}
\left(w, k_{m} \frac{\partial u}{\partial z}, k_{m} \frac{\partial v}{\partial z}, k_{h} \frac{\partial T}{\partial z}, k_{h} \frac{\partial S}{\partial z}\right) \\
=(0,0,0,0,0) \text { at } z=-H .
\end{gathered}
$$

The heat flux $\left(Q_{T}\right)$ and salinity flux $\left(Q_{S}\right)$ are given respectively by

$$
Q_{T}=Q_{h}\left(T_{a}-T_{1}\right)
$$

and

$$
Q_{S}=S_{1}[P(\phi)-E(\phi)]
$$

where $T_{a}, T_{1}, S_{1}, \mathrm{P}$ and $\mathrm{E}$ are the atmospheric temperature near the surface, first layer model temperature as well as salinity, precipitation and evaporation respectively. In this study, $Q_{h}$ is set to $50 \mathrm{cal} / \mathrm{cm}^{2} /$ day/K. The values for different constants used in these experiments are given in table 1 .

\section{Design of experiments}

The sequence of experiments is shown schematically in figure 1. The wind stress pattern for January 1979, which is used for spin-up experiment is given in figure $2(\mathrm{a})$. The ambient atmospheric temperature $\left(T_{a}\right)$ and difference of evaporation and precipitation are shown in figures $2(\mathrm{~b})$ and $2(\mathrm{c})$ respectively. Initially the ocean was at rest. At $t=0$ the mean January wind stress was switched on. For temperature and salinity the mean annual Levitus climatology are used. For the heat and salinity flux the January mean of precipitation, evaporation and ambient atmospheric temperature has been utilized. All values were obtained from AMIP archives. The model was integrated for 120 years when the system reached almost a steady state. Some of the important results of spin-up experiment are presented 
Table 1. The values of different constants used for simulation run.

\begin{tabular}{lcc}
\hline Angular rotation of the earth & $\Omega$ & $7.292 \times 10^{-5}$ \\
Radius of the earth & $a$ & $6371 \mathrm{~km}$ \\
Horizontal eddy viscosity coefficient & $A_{m}$ & $1.0 \times 10^{6} \mathrm{~m}^{2} / \mathrm{s}$ \\
Horizontal eddy diffusivity coefficient & $A_{h}$ & $2.0 \times 10^{5} \mathrm{~m}^{2} / \mathrm{s}$ \\
Vertical eddy viscosity coefficient & $k_{m}$ & $1.0 \times 10^{-4} \mathrm{~m}^{2} / \mathrm{s}$ \\
Vertical eddy diffusivity coefficient & $k_{h}$ & $1.0 \times 10^{-4} \mathrm{~m}^{2} / \mathrm{s}$ \\
Reference density of the ocean & $\rho_{0}$ & $1025 \mathrm{~kg} / \mathrm{m}^{3}$ \\
Specific heat of ocean water & $C_{p}$ & $1.0 \times 10^{-6} \mathrm{cal} / \mathrm{m}^{3} / \mathrm{K}$ \\
Depth of the ocean & $H$ & $5 \mathrm{~km}$ \\
Acceleration due to gravity & $g$ & $9.8 \mathrm{~m} / \mathrm{s}^{2}$ \\
Thermal expansion coefficient & $\alpha$ & $1.2 \times 10^{-4} / \mathrm{K}$ \\
Saline contraction coefficient & $\beta$ & $7.4 \times 10^{-6}$ \\
\hline
\end{tabular}

in the next section. Achieving the spin-up model state, further integrations were performed by using the monthly mean wind fields. At the 30 such annual cycles, the model reached an almost cyclostationary state. The results presented for this experiment are the last 10 years of the annual cycle experiment.

\section{Results and discussion}

\subsection{The spin-up experiment}

Figure 3 gives the time series of temperature along the equator at $230^{\circ}$ longitude during the spin-up experiment. This shows that the model attains almost an equilibrium state around 80 years long before the end of spin-up experiment. Figure 4(a,b and c) gives the vertically averaged horizontal barotropic stream function, surface temperature and salinity at the end of the spin-up experiment. The horizontal barotropic stream functions (figure 4(a)) appear to be realistic with more reasonable transport values for the western boundary currents, although they are smaller than observed values. These currents are broader and weaker because of coarse resolution and large constant eddy viscosity, which actually should not be taken as constant in all the regions during the model integration. It is also to be remembered that for realistic simulation of transports by different currents required the inclusion of realistic bathymetry in the model. In this experiment the Antarctic Circumpolar Current is weak with a transport value of $120 \mathrm{~Sv}$. The Gulf Stream shifted northward and it's value is large (140 Sv.). The comparison of this result with Cox's result (Pond et al 1986) depicts that Gulf Stream is strong and Circumpolar Current is weak for this model simulation. The surface temperature (figure 4(b)) shows a cold core $\left(22^{\circ} \mathrm{C}\right)$ in the coast of Peru and along the equator. This indicates the influence of strong upwelling in this region. However, its distribution in the open ocean is approximately zonal but near the coast the isotherms turn toward either north or south. This turning of isotherms arises due to deflection of currents near the coast. In some of the regions along the eastern boundary of the oceans, lower temperatures can be noted in the figure which may be

$$
120 \text { Yrs } 10 \text { Yrs } 10 \text { Yrs } 10 \text { Yrs }
$$

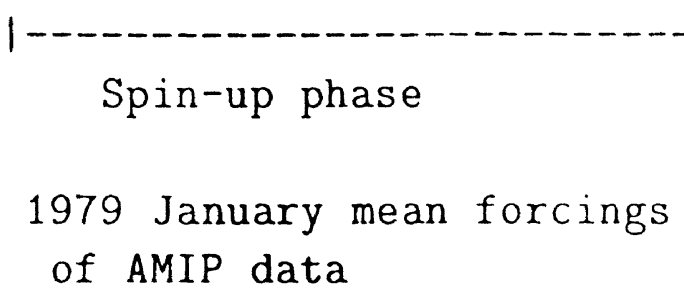

$\begin{array}{ccc}\text { 1st } & \text { 2nd } & \text { 3rd } \\ \text { cycle } & \text { cycle } & \text { cycle } \\ \text { Jan } 1979 & \text { Jan } 1979 & \text { Jan } 1979 \\ \text { to } & \text { to } & \text { to } \\ \text { Dec } 1988 & \text { Dec } 1988 & \text { Dec } 1988\end{array}$

Results

analyzed

Figure 1. Schematic diagram for the numerical simulation. 

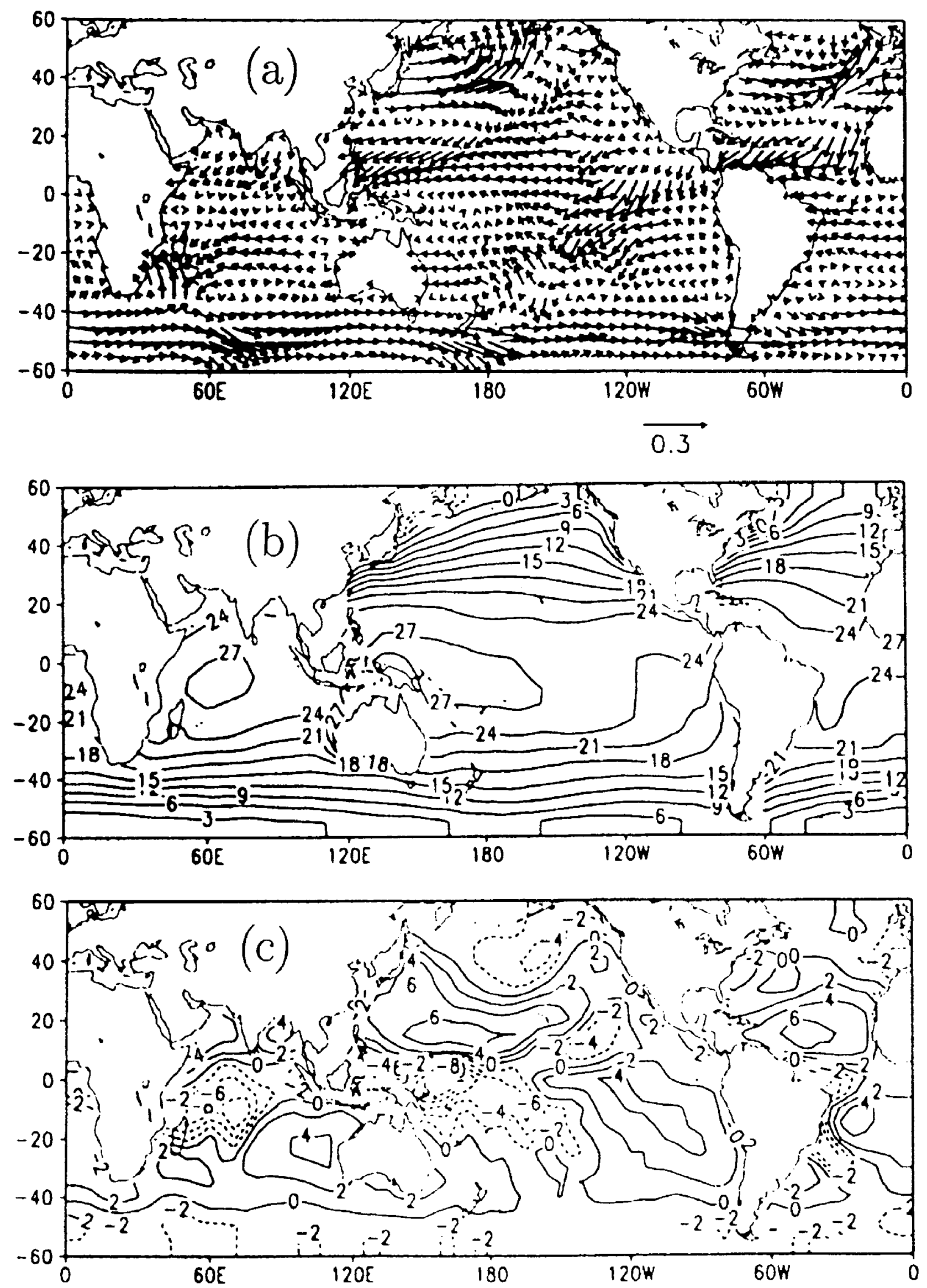

Figure 2. AMIP January mean of 1979 forcing fields used for spin-up experiment (a) wind stress, (b) ambient atmospheric temperature and (c) difference of evaporation and precipitation (E-P). 


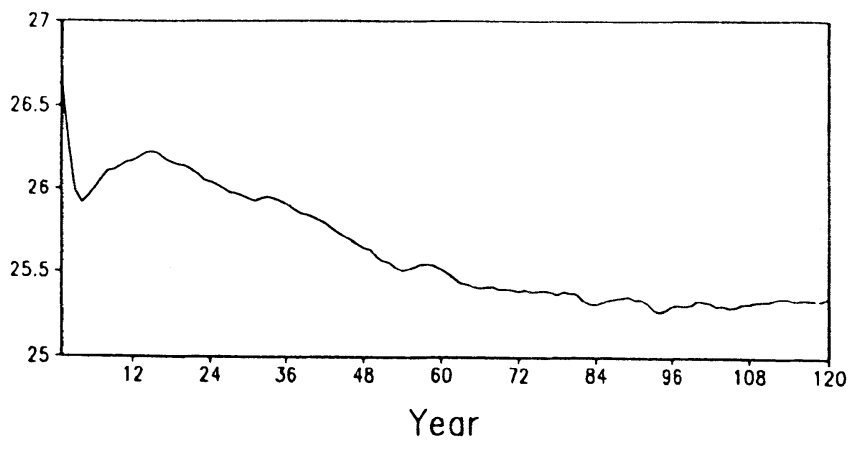

Figure 3. Time series of temperature (averaged on $5^{\circ} \mathrm{S}-5^{\circ} \mathrm{N}$ ) along the equator at $230^{\circ}$ longitude of the spin-up control run.

attributed to upwelling of cold subsurface water. The simulated surface temperatures match reasonably well with observed temperatures in this month. The salinity distribution is quite realistic. It (figure 4(c)) shows maximum salinity in the Atlantic region and this is a realistic observation. It has been observed also from this diagram like realistic observation that the Arabian Sea is more saline than the Bay of Bengal.

\subsection{The simulation experiment}

Understanding and predicting the interannual variations of the atmosphere and oceans have considerable interest in recent years. Such interest has been generated by the result of the TOGA programme, where a useful degree of predictability of a dominant mode of interannual fluctuation has been demonstrated (WCRP-89, WMO/TD No. 690). El-Niño is one of the events which has an interannual time-scale. The capability of reproducing the realistic interannual variability in the ocean gives the confidence to the ocean modellers for long term integration. This interannual variation over the oceans has been intensively investigated through observations, modelling and theoretical studies (Battisti and Hirst 1989; Zebiak 1989; Trenberth et al 1990; Barnett et al 1991; Katz 1993; Huang et al 1995) but our knowledge of the mechanism of interannual changes is limited. The interannual variability as observed in IITD-OGCM has been discussed here.

Figure 5(a) shows the time-longitude section of the model SST anomalies on the equatorial Pacific, which shows clearly the interannual variability of model SST. This variability almost looks like the observation in figure 5(b). On close inspection these figures indicate that although the magnitude of the observed and model simulated anomalies are the same in some years they show an important difference of about $+1^{\circ} \mathrm{C}$ for other years. The transport stream function variability is clearly seen from figure $5(\mathrm{c})$. It is clearly seen from this figure that this is a wave type structure. There is a striking similarity of variations observed in figure $5(\mathrm{c})$ and in figure 5(a and b) which underlines some kind of close relationship between SST and streamfunction variabilities. This is indeed true, because the changes of barotropic transport along the equator in the Pacific causes the change of Kelvin wave to Rossby wave, which is the signal of El-Niño and LaNiña events (Battisti 1988). Moreover, the easterly $(+v e)$ and the westerly (-ve) signal do not cover the entire Pacific basin in all the years. Wave structure covering the entire Pacific basin may be noted from January 1979 - November 1980 and then from January 1983 - June 1986, but for the rest of the 10 -year period such patterns are absent. This study thus, indicates that wave structure starts disappearing approximately one year before an El-Niño event as observed here for the two 1982/83 and 1987/88 El-Niño years. During these periods the transport has dramatically reduced with very small extension near the Peru coast (figure 5(c)). This indicates also that during this time the ocean water near the Peru coast preserves the heat it gained, which again decreases by some remote processes and wavy structure starts appearing. Thus, it appears that the wave activity in the region, during non-El-Niño years, is mainly responsible for the transport.

We have examined the results of the model simulated variability. From these simulation experiments one can infer the following conclusions:

- The mean state and annual cycle of the ocean are quite realistically simulated by the model.

- The model can simulate the transport for some of the important currents qualitatively not quantitatively.

- The interannual variability can be simulated with this model.

- The model can capture El-Niño type events. But in order to get realistic type events one should consider high resolution and proper heat flux formulation.

- Meridional heat transport for Pacific and Atlantic basins are comparable with other studies.

Finally, one can conclude that the model is capable of simulating some of the general features and show interannual variability of the ocean.

\section{Acknowledgements}

We express our sincere thanks to Dr. D R Sikka for his valuable suggestions and discussions during this work. This work has been supported by DST project "Four Dimensional Data Assimilation". The computing facility used for this work has been created with the help of AICTE grant under MODROB. One of the authors, Dr. Chakraborty wants to express his personal thanks to Prof. S N Gupta, Principal, Mody College of Engineering and Technology, Lakshmangarh for his interest and kind help in completing this manuscript. 

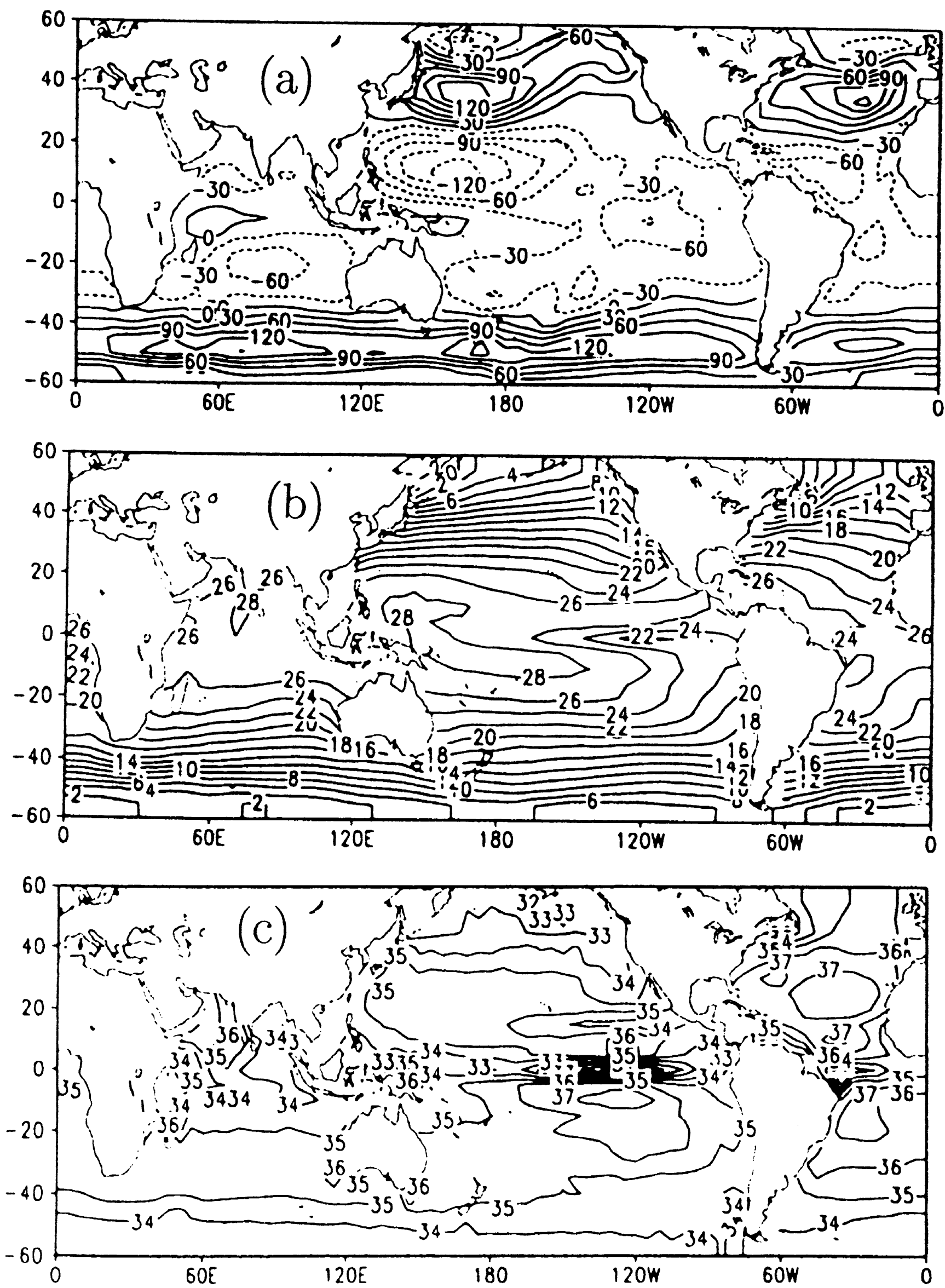

Figure 4. (a) Horizontal barotropic stream function ( $\mathrm{CI}=30 \mathrm{~Sv}, 1 \mathrm{~Sv}=10^{6} \mathrm{~m}^{3} / \mathrm{s}$ ), (b) surface temperature and (c) surface salinity of the spin-up control run. 
(a)

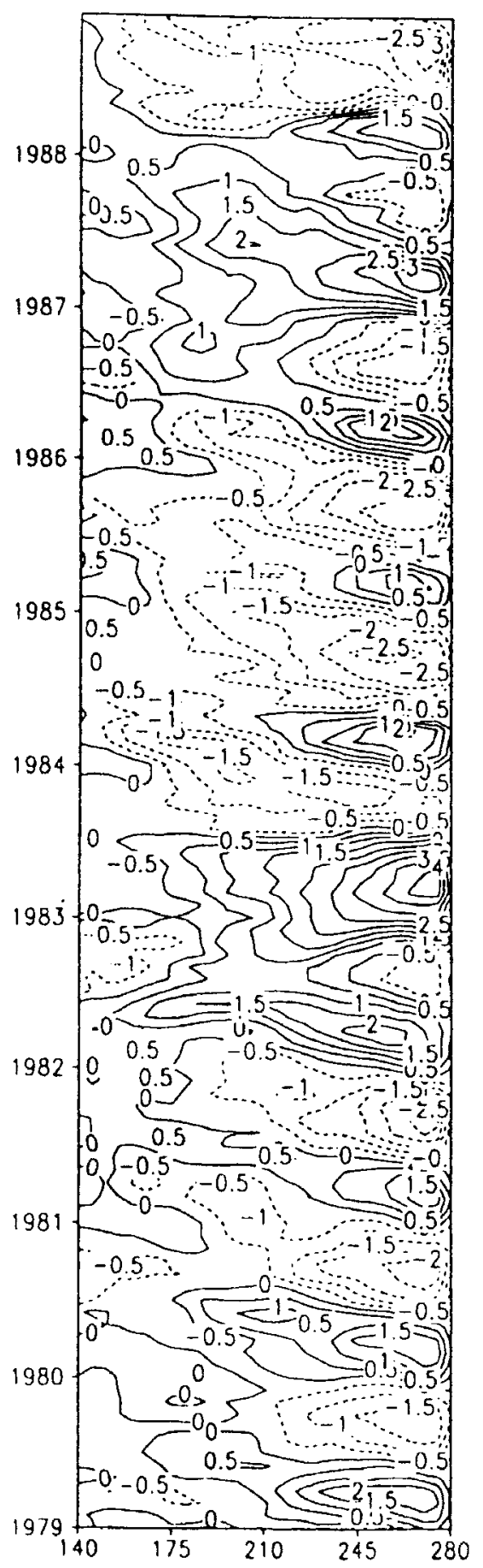

(b)

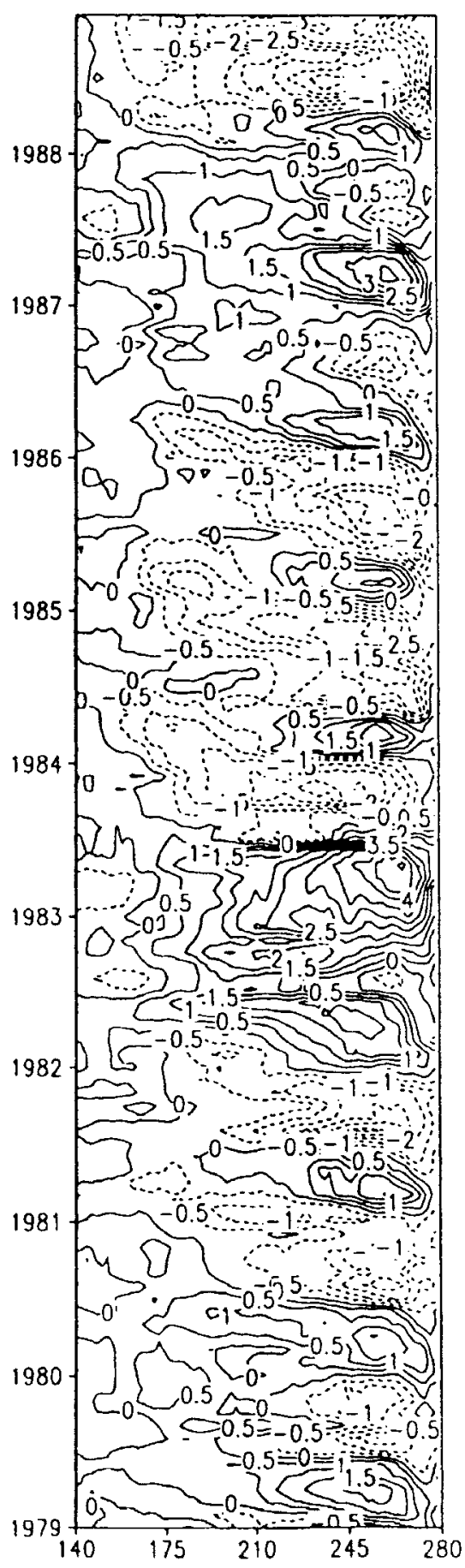

(c)

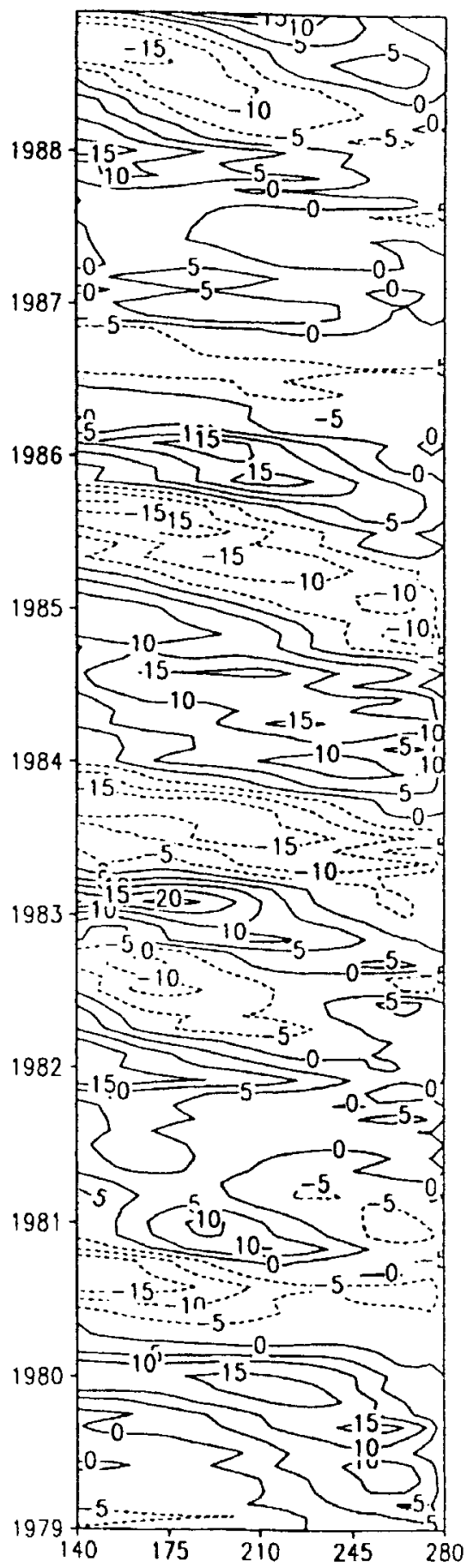

Figure 5. Time-longitude section (averaged on $5^{\circ} \mathrm{S}-5^{\circ} \mathrm{N}$ ) along the equator in the Pacific region: SST anomalies for (a) model simulation and (b) observation; (c) transport stream function anomalies ( $\mathrm{CI}=5 \mathrm{~Sv})$.

\section{References}

Barnett T P, Latif M, Krik E and Roeckner E 1991 On ENSO physics; J. Climate 4 487-515

Battisti D S 1988 The dynamics and thermodynamics of a warming event in a coupled tropical atmosphere/ocean model; J. Atmos. Sci. 45 2889-2919

Battisti D S and Hirst A C 1989 Interannual variability in the tropical atmosphere-ocean system: Influence of the basic state and ocean geometry; J. Atmos. Sci. 46 1687-1712

Broecker W S 1991 The great ocean conveyor; Oceanography 4 79-89

Chakraborty A, Upadhyaya H C and Sharma O P 1998 Evolution of temperature and salinity fields in a global ocean model; Indian J. Mari. Sci. (accepted for publication)

Delecluse P, Madec G, Imbard M and Levy C 1993 Ocean General Circulation Model Reference Manual; Technical Report, LODYC 93/05, September 1993, 113pp. 
Huang B and Schneider E K 1995 The response of an ocean general circulation model to surface wind stress produced by an atmospheric general circulation model; J. Atmos. Sci. 123 3059-3085

Katz E J 1993 An interannual study of the atlantic north equatorial current; J. Phys. Oceanogr. 23 116-123

Latif M 1987 Tropical ocean circulation experiments; J. Phys. Oceanogr. 17 246-263

Mechoso C R and Coauthors 1995 The seasonal cycle over the tropical pacific in coupled ocean-atmosphere general circulation models; J. Atmos. Sci. 123 2825-2838

Philander S G H and Pacanowski R C 1980 The generation of equatorial currents; J. Geophys. Res. 85 1123-1136

Philander S G H 1981 The response of equatorial oceans to a relaxation of the trade wind field; J. Phys. Oceanogr. 11 176-189

Philander S G H and Pacanowski R C 1981 Response of equatorial oceans to periodic forcing; J. Geophys. Res. 86(C3) 1903-1916

Pond S and Pickard G L, 1986 Introductory Dynamical Oceanography; (England: Pergamon Press Ltd.) 197pp.
Sadourny R 1975 The dynamics of finite-difference models of the shallow-water equations; J. Atmos. Sci. 32 680-689

Sharma O P, Upadhyaya H C, Braine-Bonnaire T H and Sadourny R 1987 Experiments on regional forcasting using a stretched-coordinate general circulation model; J. Meteorol. Soc. Japan, Spl. Vol. 263-271

Stockdale T, Anderson D, Davey M, Delecluse P, Kattenberg A, Kitamura Y, Latif M and Yamagata T 1993 Intercomparison of tropical ocean GCMs; WRCP-79, WMO/TD-No. 545, 43pp plus figs.

Trenberth K E, Large W G and Olson J G 1990 The mean annual cycle in global ocean wind stress; J. Phys. Oceanogr. 20 1742-1760

Weaver A J and Hughes T M C 1992 Stability and variability of the thermohaline circulation and its link to climate; Trends in Physical Oceanography, Research Trends Series, Council of Scientific Research Integration, $56 \mathrm{pp}$.

Zebiak S E 1989 Ocean heat content variability and El-Niño cycles; J. Phys. Oceanogr. 19 475-485 